Manuelle Medizin 2018 · 56:340

https://doi.org/10.1007/s00337-018-

0432-3

(c) Springer Medizin Verlag $\mathrm{GmbH}$, ein

Teil von Springer Nature 2018

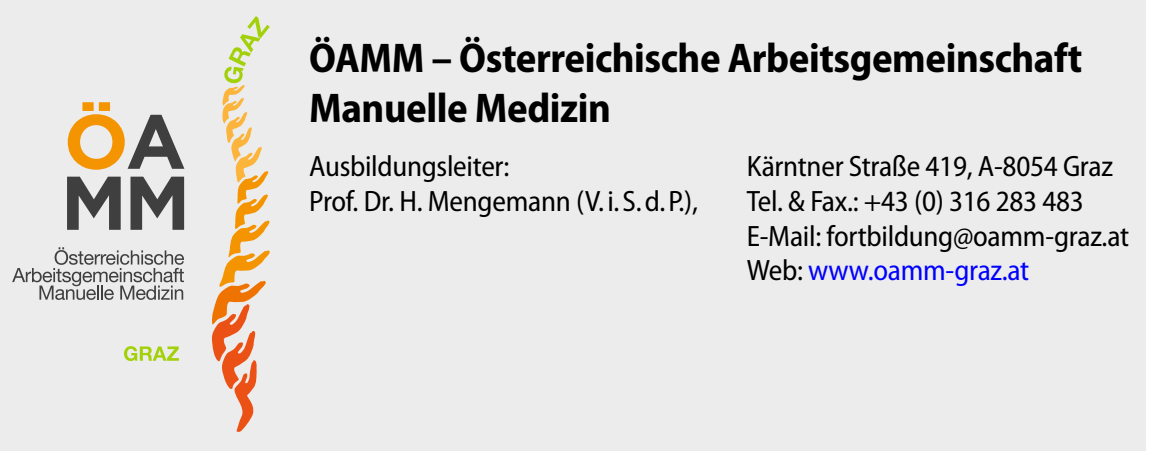

\section{Kurse 2018}

\section{Kurs 1}

22.09.-29.09.2018

Kurs 2

11.10.-14.10./18.10.-21.10. Bad Häring

Kurs 3

20.10.-27.10.2018

Kurs 4

08.09.-15.09.2018

Kurs 5

01.12.-08.12.2018

Refresher Wochenende

17.11.-18.11.2018

\section{Kurse 2019}

\section{Kurs 1}

$\begin{array}{ll}\text { 20.01.-27.01.2019 } & \text { Wien } \\ \text { 02.03.-09.03.2019 } & \text { Graz } \\ \text { 20.06.-23.06./27.06.-30.06. } & \text { Bad Häring } \\ \text { 21.09.-28.09.2019 } & \text { Graz }\end{array}$

KA1911

KA1912

KA1913

KA1914

\section{Kurs 2}

12.01.-19.01.2019

05.05.-12.05.2019

29.06.-06.07.2019

Graz
Wien
Graz
Bad Häring
Graz

10.10.-13.10./17.10.-20.10

07.12.-14.12.2019

Graz

\section{Kurs 3}

28.02.-03.03./07.03.-10.03.

30.03.-06.04.2019

14.09.-21.09.2019

05.10.-12.10.2019

\section{Kurs 4}

02.02.-09.02.2019

07.09.-14.09.2019

\section{Kurs 5}

18.05.-25.05.2019

23.11.-30.11.2019

\section{Sonderkurse}

18.03.-22.03.2019

09.11.-10.11.2019

\section{Bad Häring \\ Graz \\ Wien \\ Graz}

Graz

Graz

Graz

Graz

St. Johann

Loipersdorf
KA1921

KA1922

KA1923

KA1925

KA1931

KA1932

KA1933

KA1934

KA1941

KA1942

KA1951

KA1952

\section{Ausbildungsziel}

Das Erlernen von klinisch-manuellen Untersuchungstechniken am Stütz- und Bewegungssystem zur therapeutischen Beeinflussung von reversiblen Funktionsstörungen.

Die Fortbildung dient damit der Erweiterung des Angebotes der kurativen, rehabilitativen und präventiven Medizin.

\section{Zielgruppe}

ÄrztInnen für Allgemeinmedizin und FachärztInnen aller Sonderfächer.

\section{Teilnahmevoraussetzung}

Frühest möglicher Beginn der Fortbildung ist nach der Promotion.

\section{Weiterbildungsdauer/Stundenerfordernis}

Mindestens 1,5 Jahre, nach den Richtlinien der Österreichischen Ärztekammer sind für das ÖÄK Diplom Manuelle Medizin insgesamt 300 Fortbildungsstunden (100 Stunden Theorie, 200 Stunden Praxis und Demonstrationen) erforderlich.

KA 1924

\section{Wesentliche Inhalte}

Erkennen und Behandeln mit den Händen

Von der Arbeitshypothese zur Diagnose

Prävention

Rezidivprophylaxe

Terminänderungen/Absagen vorbehalten.

Wir weisen darauf hin, dass für die Kursteilnehmer der ÖAMM die Kurszeiten und Anwesenheitspflicht bindend sind!

Die Bestätigung der Fortbildungspunkte durch die österreichische Ärztekammer ist an die Erfüllung der Kursrichtlinien gebunden.

Verbindliche Anmeldungen und Auskünfte im Sekretariat der ÖAMM E-Mail: fortbildung@oamm-graz.at

Internet: www.oamm-graz.at Adresse: Kärntner Straße 419, $8054 \mathrm{Graz}$ 